Polymer Journal, Vol. 9, No. 2, pp 167-172 (1977)

\title{
Active Polycondensation of Cyclic Derivatives of Succinate with Hexamethylenediamine
}

\author{
Naoya Ogata and Yoshikazu Hosoda \\ Department of Chemistry, Sophia University, \\ 7, Kioi-cho, Chiyoda-ku, Tokyo 102, Japan.
}

(Received November 12, 1976)

\begin{abstract}
Epoxy and formal derivatives of tartarate were found to be easily subjected to polycondensation reactions with hexamethylenediamine (HMD) in solutions under mild conditions and linear polyamides having epoxy or formal groups were obtained in a quantitative yield. The polycondensation reaction of epoxy succinate with HMD was influenced by solvents and a competitive reaction between a nucleophilic attack of amine to ester and epoxy groups was also influenced by solvents.

Thus, a cross-linked polyamide was obtained from epoxy succinate and HMD. On the other hand, a linear polyamide was obtained from formal tartarate and HMD. The polyamide from formal tartarate and HMD suffered a cross-linked reaction among the formal groups on heating.

KEY WORDS Polycondensation / Epoxy Polyamide / Formal Polyamide / Polyamide / Tartarate / Moisture Absorption /
\end{abstract}

A polycondensation reaction of diesters with diamines is usually carried out in a molten state at elevated temperature so as to eliminte an alcohol out of the reaction phase, since the polycondensation is under the control of equilibrium. If one wants to carry out the polycondensation under mild conditions, one has to enhance the reactivity of the diesters by a suitable method, such as the use of acid chloride.

It was reported in previous papers ${ }^{1,2}$ that hydroxyl diesters such as tartarate or mucate are easily subjected to polycondensation reactions with diamines in solutions even at room temperature to form linear polyamides having pendant hydroxyl groups. It was also found $d^{3,4}$ that the reactivity of diesters having an ether group at a position $\alpha$ or $\beta$ to the ester carbonyl group is enhanced to such an extent that the polycondensation reaction with diamines occurs in solutions under mild conditions. Therefore, the following derivatives of succinate having epoxy or formal groups were expected to have a high reactivity toward polycondensation, since these derivatives have ether groups at the $\alpha$ position of the ester group:<smiles>COC(=O)C1OC(C(=O)OC)C1OC</smiles><smiles>COC(=O)C(OC)C(C)OC</smiles>

Conventional melt polycondensation of these epoxy or formal diesters with diamines causes various side reactions including cross-linking or thermally decomposing reactions and thus it is almost impossible to obtain a linear polyamide under such severe conditions as occur in carrying out the reaction at elevated temperatures. If these cyclic derivatives of succinate could react with diamines in solutions under mild conditions, a linear polyamide having epoxy or formal groups would be obtained and one route to synthesize functional condensation-type polymers would be opened. This paper describes optimum reaction conditions to obtain linear functional polyamides from cyclic derivatives of succinate with hexamethylenediamine under mild conditions.

\section{EXPERIMENTAL}

\section{Monomer Synthesis}

Dimethyl Epoxysuccinate (MES). 2,3-Epoxy succinic acid was synthesized by the oxidation of maleic anhydride with an alkaline hydrogen 


\section{N. Ogata and Y. Hosoda}

peroxide. $^{5}$ To a $300-\mathrm{m} l$ aqueous solution of $98 \mathrm{~g}$ of maleic anhydride and $50 \mathrm{~g}$ of sodium hydroxide were added $1.2 \mathrm{~mol}$ of $30 \%$ aqueous hydrogen peroxide in the presence of $6.6 \mathrm{~g}$ of sodium tangustate at $70^{\circ} \mathrm{C}$, and the solution was stirred for $1 \mathrm{hr}$. After acidifying the solution with $\mathrm{HCl}$, epoxysuccinic acid was precipitated and this was collected by filtration.

Epoxysuccinic acid $(98 \mathrm{~g})$ was allowed to react $^{6}$ with $340 \mathrm{~g}$ of phosphorous pentachloride; epoxysuccinyl chloride was obtaind in 58\% yield after distillation. bp $56-58^{\circ} \mathrm{C} / 1 \mathrm{mmHg}$. Epoxysuccinyl chloride was converted to dimethyl epoxysuccinate (MES) by reacting with methanol in benzene in the presence of triethylamine. Yield, $73 \%$; bp $75-78^{\circ} \mathrm{C} / 1 \mathrm{mmHg}$. Found: C, 45.0\%; H, 5.04\%. Calcd: C, 44.25\%; $\mathrm{H}, 4.91 \%$.
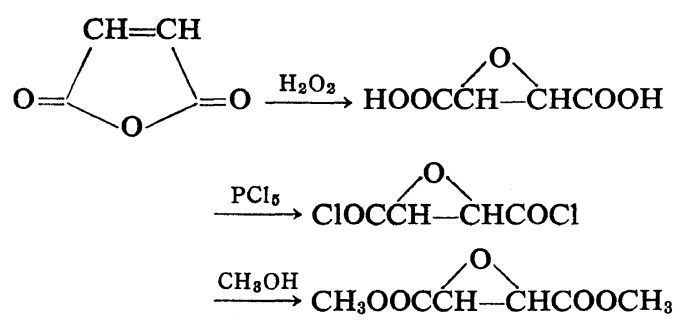

Dimethyl Methylenetartarate $(M T)$. Dimethyl tartarate $(89 \mathrm{~g})$ and trioxane $(45 \mathrm{~g})$ were allowed to react $^{7}$ at $70^{\circ} \mathrm{C}$ for 3 days in the presence of $10 \mathrm{~g}$ of sulfuric acid. After neutralyzing the solution with sodium carbonate, dimethyl methylenetartarate was extracted with ether and distilled in vacuum. Yield, $20 \%$; bp $120^{\circ} \mathrm{C} / 2$ $\mathrm{mmHg}$. Found: C, 43.01\%; H, 5.08\%. Calcd: C, $44.22 \% ; \mathrm{H}, 5.30 \%$.

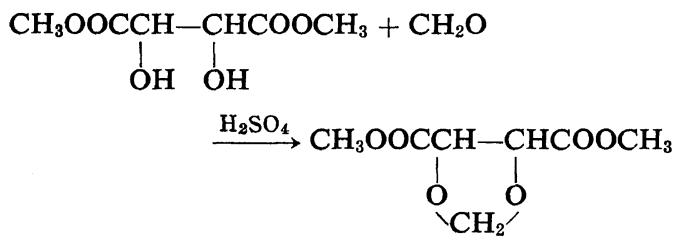

\section{Polycondensation}

Equimolar amounts of MES or MT with hexamethylenediamine (HMD) were dissolved in various solvents and the solutions were allowed to stand with stirring at given temperatures. The rate of the polycondensation was quantitatively determined either by measuring the amount of liberated methanol by means of gaschromatography or by titrating the amount of residual HMD in the solutions with 0.1-N $\mathrm{HCl}$. Polymers were isolated from the solutions by evaporating solvents in vacuum, followed by washing with acetone and drying.

\section{Model Reaction}

$N, N^{\prime}$-Dibutyl-2,3-epoxysuccinamide (DES) was synthesized from epoxysuccinyl chloride and $n$-butylamine in THF in the presence of triethylamine. Equimolar amouts of DES and $n$-butylamine were allowed to react in various solvents at $30^{\circ} \mathrm{C}$ and the residual amount of $n$-butylamine in the solution was determined by gaschromatographic analysis so that the ring-opening reaction of the epoxy group of DES by a nucleophilic attack of amine, as a model of a side reaction, could be distinguished from the condensation reaction.

\section{Characterization}

Polymers were identified by elemental and infrared analyses. Thermal behaviors of the polymers were measured by thermogravimetric (TGA) and differential thermal (DTA) analyses, using Rigakudenki thermoflex 8001. Moisture absorptions of the polymers were determined by weight increases after dried polymers were kept in atmospheres with given relative humidities.

\section{RESULTS AND DISCUSSION}

\section{Polycondensation of MES}

Results of the polycondensation of MES with HMD in dimethylformamide (DMF) at various temperatures are indicated in Figure 1, where it is seen that the polycondensation reaction takes place even at room temperature. Raised temperatures accelerated the polycondensation at the initial stage, while the reaction rate retarded rapidly after a certain period of time at elevated temperatures.

Temperatures above room temperature caused a rapid gelation of the solution, apparently because the ring-opening reation of the epoxy groups in polymer chains with an amino group occurs as a side reaction to form a crosslinked polymer. This gelation phenomenon might retard the polyocndensation at elevated temperatures, since the polycondensation still con- 


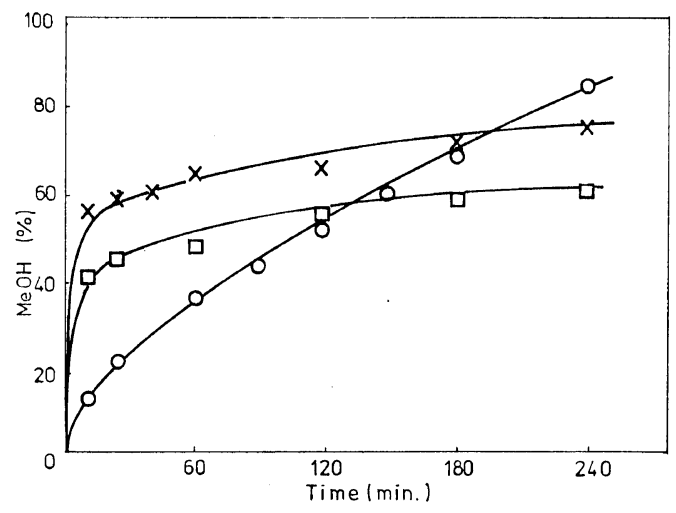

Figure 1. Polycondensation of MES with HMD at various temperature: monomer concn, $1 \mathrm{~mol} / l$; solvent, DMF; $\bigcirc$, room temp; $\square, 60^{\circ} \mathrm{C} ; \times, 100^{\circ} \mathrm{C}$.

tinued slowly to a complete reaction of diamine.

Polycondensation of MES with HMD was carried out at room temperature in various solvents; the results are summarized in Figure 2. As shown in Figure 2, apparent polycondensation rates were dependent on solvents used; hexamethylphosphortriamide (HMPA) was the most suitable solvent among those tested in terms of the rate and the apparent fluidity of the solution.

The polycondensation reaction of MES with HMD proceeded in an homogeneous solution and no polymer was precipitated during the

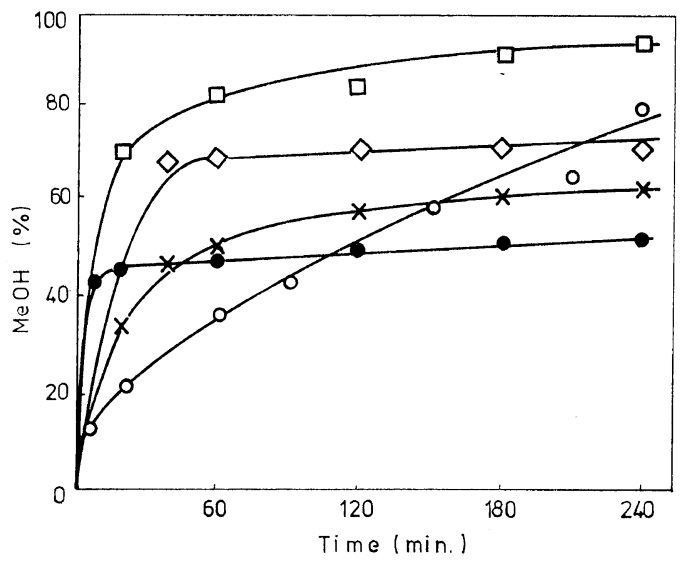

Figure 2. Polycondensation of MES with HMD in various solvents: monomer concn, $1 \mathrm{~mol} / l$, room tem; $\square$, HMPA; $\diamond$, benzyl alcohol; $\times$, DMSO; $\bigcirc$, DMF; O, DMSO. polycondensation. However, as described before, gelation of the solution occured and the apparent fluidity of the solution depended on solvents. Particularly, the gelation of the polymer solution took place rapidly in dioxane. Therefore, the solvent effect on the polycondensation rate should be discussed in terms of not only the reactivity change of functional groups due to the polarity of the solvents, but also the physical mobility of polymer chains due to the gelation.

Figure 3 indicates the polycondensation of MES with HMD in the presence of $5 \mathrm{~mol} \%$ of alkali metal alkoxide, where it is seen that the polycondensation is greatly accelerated by alkoxides in the following order: $\mathrm{KOCH}_{3}>$ $\mathrm{NaOCH}_{3}>\mathrm{LiOCH}_{3}$.

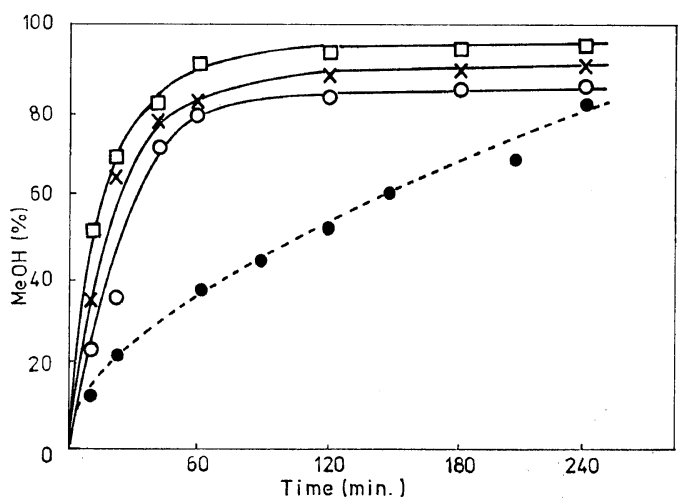

Figure 3. Polycondensation of MES with HMD in the presence of various alkali metal alkoxides: monomer concn, $1 \mathrm{~mol} / l$, room temp; $\square$, KOMe; $\times$, NaOMe; $\bigcirc$, LiOMe; $\bigcirc$, none.

The infrared spectrum of the polymer from MES and HMD is shown in Figure 4, where typical absorptions owing to amide and epoxy groups are observed. Elemental analysis of the polymer was consistent with calculated values as follows: C, 56.50\%; H, 7.45\%, N, 13.54\%. Calcd: C, $56.60 \% ; \mathrm{H}, 7.55 \%$; N, $13.20 \%$.

Therefore, the polymer from MES and HMD was identified as the polyamide with a corresponding structure. However, the collected polymers did not dissolve in any solvents including sulfuric acid, indicating a cross-linked structure. The cross-linking reaction of the polymers might take place at the epoxy group during the 


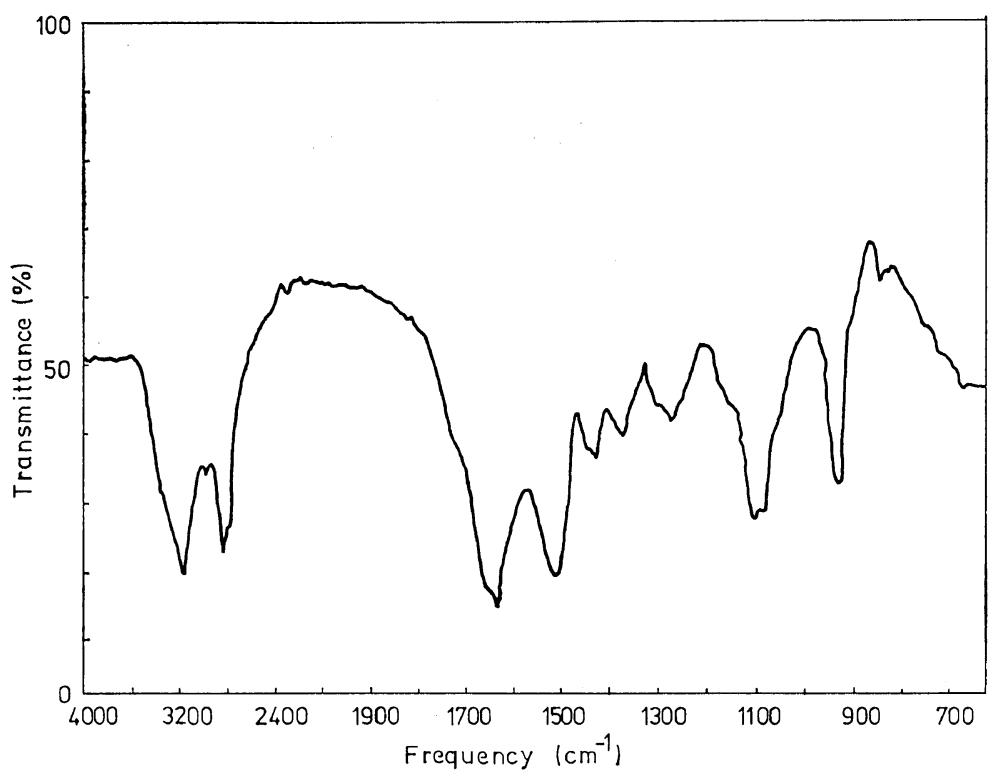

Figure 4. IR spectrum of polyamide from MES and HMD.

polycondensation and also during the drying process of the polymers. The polyamide from MES and HMD decomposed on heating at around $200^{\circ} \mathrm{C}$.

In order to investigate the ring-opening reaction of the epoxy group in the polymer chains, a model reaction was carried out. $N, N$-Dibutyl2,3-epoxysuccinamide was allowed to react with $n$-butylamine in various solvents at room temperature.

$$
\begin{gathered}
\text { BuNHCOCH}-\mathrm{CHCONHBu}+n-\mathrm{BuNH}_{2} \\
\underset{(\mathrm{DES})}{\longrightarrow} \mathrm{BuNHCOCH}-\mathrm{CHCONHBu} \\
\text { OH }{ }_{\mathrm{NHBu}}
\end{gathered}
$$

Figure 5 indicates the ring-opening reaction of the epoxy group of DES in terms of the consumption of $n$-butylamine in the solutions. The ring-opening reaction was found to take place rapidly in dioxane. This result was consistent with the rapid gelation of the solution during the polycondensation in dioxane.

\section{Polycondensation of MT}

The polycondensation rate of MT with HMD was determined by using various solvents, as

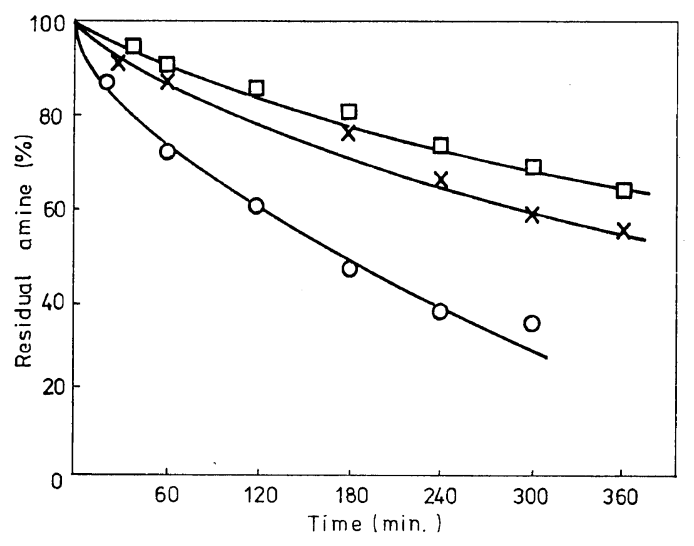

Figure 5. Ring-opening reaction of the epoxy group of MDS diamide derivatives in various solvents: monomer concn, $1 \mathrm{~mol} / l$, room temp; DMF; $\times$, DMSO; $\bigcirc$, dioxane.

shown in Figure 6.

The polycondensation of MT with HMD was carried out in methanol at room temperature in the presence of $5 \mathrm{~mol} \%$ of alkali metal alkoxide or mineral acids as an accelerator. It was found that the addition of these bases or acids rather retarded the polycondensation of MT. On the other hand, the addition of Lewis acids such as calcium chloride accelerated the polycondensa- 


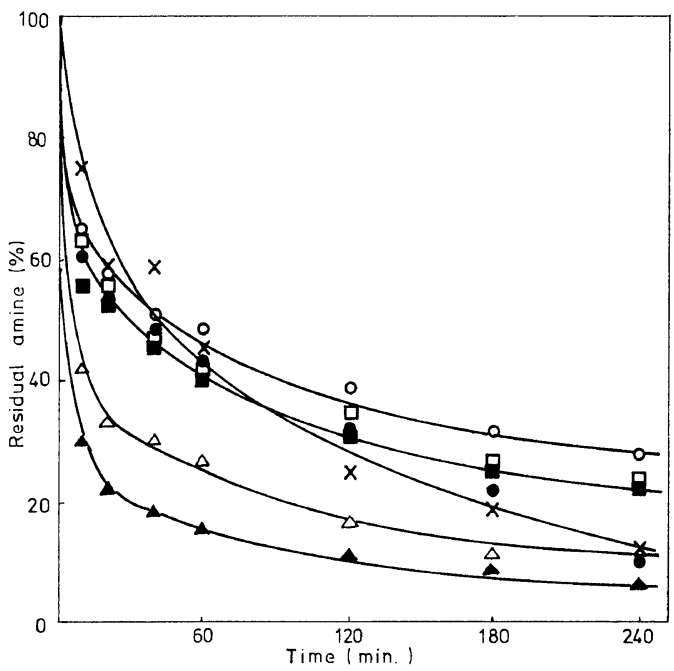

Figure 6. Polycondensation of MT with HMD in various solvents: monomer concn, $1 \mathrm{~mol} / l$, solvent, methanol, room temp; $\bigcirc$, THF; $\square$, DMAc; $\square$, NMP; ๑, HMPA; $\times$, benzylalcohol; $\triangle$, methanol; $\triangle$, methanol/water (50/50).

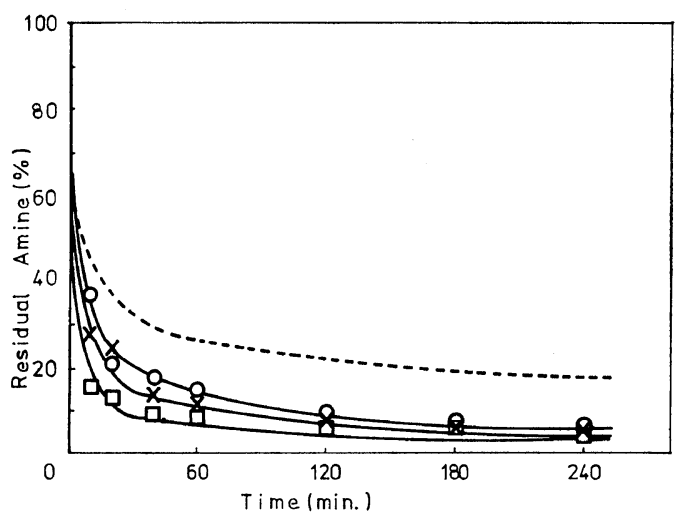

Figure 7. Polycondensation of MT in the presence of various salts: Monomer concn, $1 \mathrm{~mol} / \mathrm{l}$, solvent, methanol, room temp; $\bigcirc, \mathrm{ZnCl}_{2} ; \times, \mathrm{LiCl} ; \square$, $\mathrm{CaCl}_{2}, 10 \mathrm{wt} \% ;---$, none.

Table I. Polycondensation of MT with HMD at room temperature. ${ }^{\mathrm{a}}$

\begin{tabular}{lccccc}
\hline Solvent & $\begin{array}{c}\text { Polymer } \\
\text { yield }\end{array}$ & $\eta_{\mathrm{sp} / \mathrm{c}}$ & $\mathrm{C}, \%$ & $\mathrm{H}, \%$ & $\mathrm{~N}, \%$ \\
\hline Methanol & 87.6 & 0.24 & 54.9 & 6.51 & 11.03 \\
THF & 80.2 & 0.16 & 55.1 & 6.60 & 11.50 \\
\hline
\end{tabular}

. Calcd. $\mathrm{C}=55.0 \%, \mathrm{H}=6.67 \%, \mathrm{~N}=11.67 \%$

Monomer concn, $1 \mathrm{~mol} / \mathrm{l}$. tion reaction of MT with HMD, as shown in Figure 7.

While the polycondensation of MT seemed to reach an apparent equilibrium within $2 \mathrm{hr}$, the reaction was completed only after a week, and those results of the polycondensation are summarized in Table I. The polymers were identified as a corresponding polyamide (polyamide MT) from MT and HMD, as reported in a previous paper. ${ }^{8}$ The polyamide MT could easily

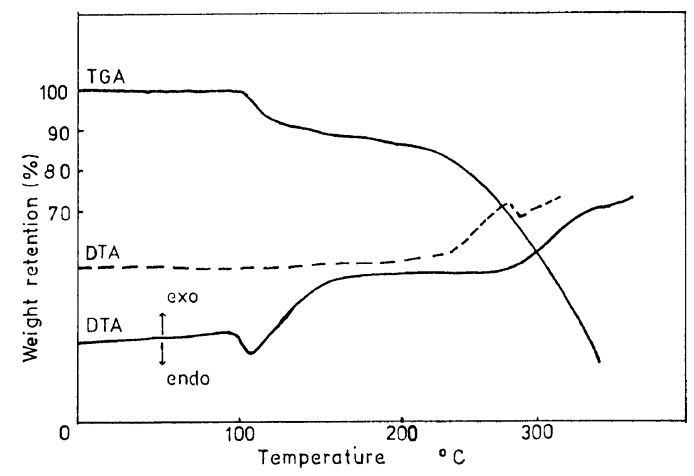

Figure 8. DTA or TGA analyses of the polyamide from MT with HMD.

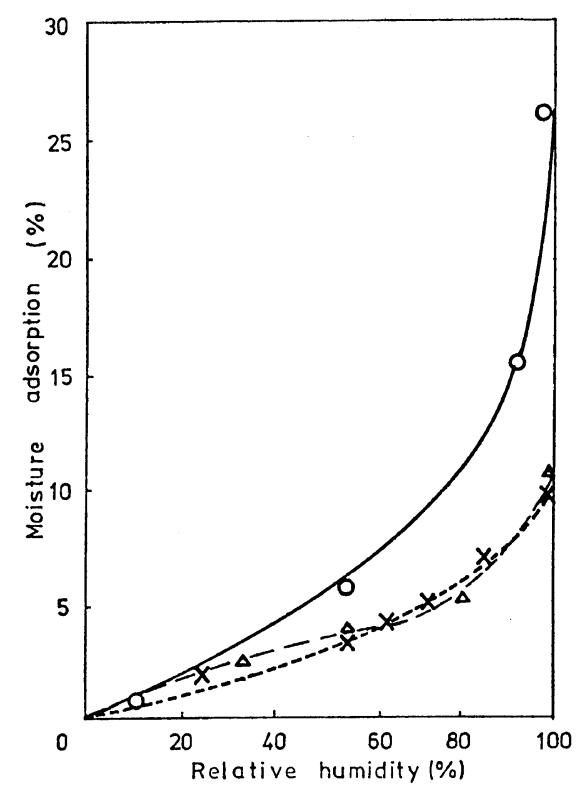

Figure 9. Moisture adsorption of the polyamide from $\mathrm{MT}$ and $\mathrm{HMD}$ at $25^{\circ} \mathrm{C}$ : -, polymer from MT; ---, nylon 6; ---, polymer from L-tartarate. 


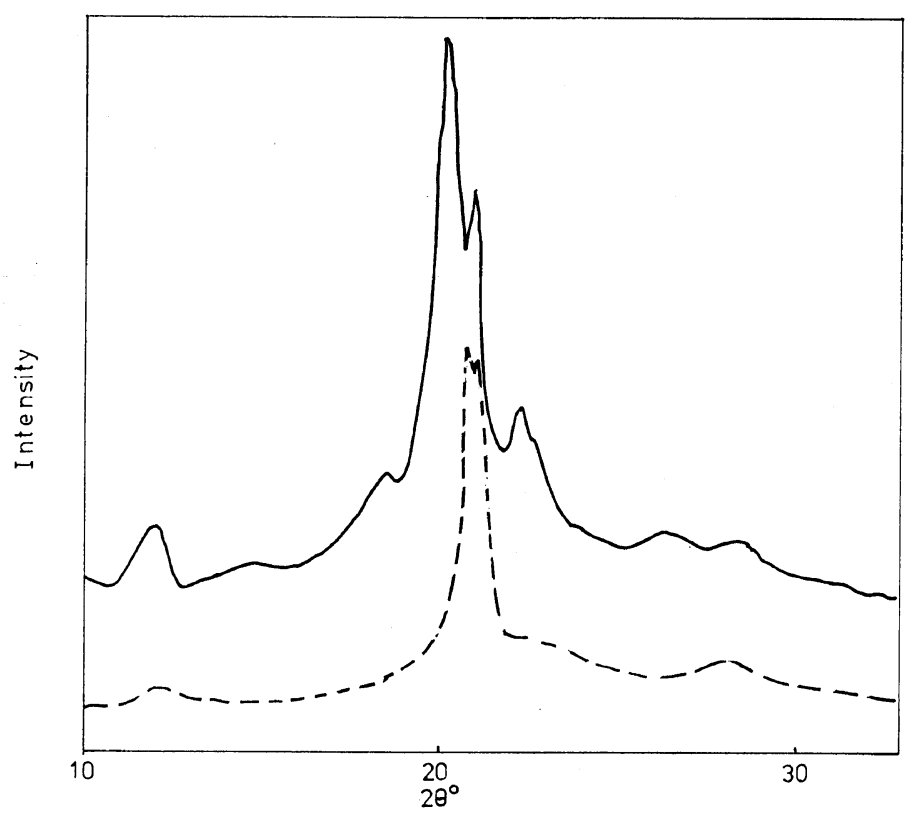

Figure 10. X-ray diffraction diagrams of polyamides: -, MT and HMD; ---, L-tartarate and HMD.

dissolve in methanol, THF, DMF or dimethylsulfoxide and was partially soluble in water, while it was insoluble in acetone.

The thermal behavior of the polyamide in terms of TGA and DTA is shown in Figure 8, where no distinct melting phenomenon was observed. An endothermic peak and a weight loss at $100^{\circ} \mathrm{C}$ might be due to water absorbed in the polyamide. The polyamide MT started to decompose at $250^{\circ} \mathrm{C}$. The polyamide $\mathrm{MT}$ transformed into a cross-linked polymer on heating at $200^{\circ} \mathrm{C}$ and the formal side groups might cause the cross-linking reaction among the polymer chains.

The polyamide MT powder cast from THF solution had an amorphous structure and had a high moisture absorption in comparison with nylon 6, as showin in Figure 9. On the other hand, the polyamide MT powder precipitated with acetone had a very high crystalline structure, as can be seen in the sharp X-ray reflec- tion peaks in Figure 10, and the crystalline polyamide MT had a moisture absorption as low as nylon 6.

\section{REFERENCES}

1. N. Ogata and Y. Hosoda, J. Polym. Sci., Polym. Chem. Ed., 13, 1793 (1976).

2, N. Ogata, K. Sanui, Y. Hosoda, and H. Nakamura, ibid., Polym. Chem. Ed., 14, 783 (1976).

3. N. Ogata, K. Sanui, and K. Ohkouchi, Polym. J., 5, 186 (1973).

4. N. Ogata, Y. Hosoda, and G. Suzuki, ibid., 6, 412 (1974).

5. G. B. Payne and P. H. Williams, J. Org. Chem., 24, 54 (1959).

6. T. W. Campbell and R. N. Mcdonald, J. Polym. Sci., Part A-1, 1, 2525 (1963).

7. C. A. de Bruyn and W. Alberda van Ekenstein, Rec. Trav. Chim., 21, 313 (1902).

8. N. Ogata and Y. Hosoda, J. Polym. Sci., Polym. Lett. Ed., 14, 409 (1976). 